PLURAL, Revista do Programa de Pós-Graduação em Sociologia da USP, São Paulo, v. 16, n. 1, pp. 145-155, 2009

\title{
Identidades Culturais e Mobilidade Migratória: Estudo de Caso sobre a Identidade Diaspórica Hindu
}

\section{Mirian Santos Ribeiro de Oliveira*}

Resumo: A complexidade dos processos de construção de identidades culturais - em um contexto de intensificação e diversificação de fluxos migratórios, característico dos processos de globalização contemporâneos - está associada à coexistência de tendências à homogeneidade e à heterogeneidade, bem como à possibilidade de que tais identidades sejam construídas a partir da sociedade de origem ou da sociedade de destino. Este artigo analisa dois aspectos da construção de identidades diaspóricas por meio de um estudo de caso sobre uma identidade diaspórica específica, a "hinduidade" (Hindutva): (I) a relação entre as dimensóes nacional e transnacional, em uma concepção de identidade diaspórica elaborada a partir da sociedade de origem; (2) a definiçáo de uma identidade diaspórica em termos religiosos.

Palavras-chave: diásporas. identidades culturais; mobilidade migratória; Índia; nacionalismo hindu contemporâneo.

\section{Cultural Identities and Migratory Mobility: Case Study on Hindu Diasporic Identity}

Abstract: The complexity of cultural identities construction - in a context of increasingly intense and diverse migratory flows, characteristic of contemporary globalization processes - is related to the coexistence of trends toward homogeneity and heterogeneity, as well as to the possibility of constructing such identities from the homeland or from host societies. Through a case study on Hinduness (Hindutva), a Hindu diasporic identity, this article looks into processes of diasporic identities construction, stressing particularly: (I) the relationship between national and transnational dimensions in a diasporic identity constructed from the homeland; (2) the religious definition of such diasporic identity.

Keywords: diasporas; cultural identities; migratory mobility; India; contemporary hindu nationalism.

* Bacharel em Relaçóes Internacionais (PUC-Minas); mestre em Sociologia (UFMG); doutoranda em Sociologia (USP). 


\section{INTRODUÇÃO}

A partir da segunda metade do século XX, paralelamente à intensificação dos processos de globalização, constrói-se uma percepção otimista sobre as diásporas. Visto que a mobilidade se torna um elemento central nas sociedades contemporâneas e que, em decorrência disso, processos transnacionais adquirem cada vez mais relevância, confere-se nova legitimidade a noçóes de pertença transnacionais existentes anteriormente, como é o caso das identidades diaspóricas. $\mathrm{Na}$ medida em que as migraçôes adquirem um caráter crescentemente transnacional e que, portanto, os fluxos migratórios se autonomizam em relação às sociedades de origem e de destino, observase, por um lado, que os debates sobre integração/assimilação dos migrantes perdem importância e, por outro lado, que a multiplicidade de referências e de valores, característica das diásporas - associada, na maioria das vezes, à flexibilidade e hibridez -, passa a ser considerada positiva (Peralva, 2008; Schnapper, 200I).

É possível perceber, ainda no período em questão, que a utilização do termo diáspora se tornou mais frequente, e ele, mais amplo e flexível; antes empregado para designar grupos sociais que, apesar de geograficamente dispersos em Estados diferentes, mantinham vínculos (materiais e simbólicos) entre si e com suas sociedades de origem - como grupos de judeus, armênios, gregos e chineses que migraram em decorrência de perseguiçóes políticas ou de empreendimentos comerciais.

O vocábulo, atualmente, refere-se a todas as formas de dispersão de populaçóes humanas (Schnapper, op. cit.). Tal flexibilização do uso do termo pode ser notada tanto no que se refere a pesquisadores de temas relativos a diásporas como no que diz respeito a membros de grupos diaspóricos.

Em meio à proliferação de conceitos de diáspora e de autodefiniçôes como diáspora, optou-se, neste artigo, por adotar uma autodefinição - "diáspora hindu" ou "mundo hindu", presente no discurso nacionalista hindu contemporâneo - como ponto de partida para a análise da construção de identidades culturais na fase contemporânea dos processos de globalização.

Nas seçóes seguintes, serão destacados e problematizados dois aspectos da presença de um tratamento sobre a diáspora em um discurso nacionalista: a relação entre as dimensóes nacional e transnacional, em uma concepção de identidade diaspórica elaborada a partir da sociedade de origem; e a definição de uma identidade diaspórica em termos religiosos.

\section{"HINDUIDADE": A CONSTRUÇÃO DE UMA IDENTIDADE (TRANS)NACIONAL}

Desde o século XIX, o movimento nacionalista indiano foi marcado pela coexistência de correntes de pensamento divergentes, principalmente no que se refere à relaçáo entre religiáo e política: nacionalismo hindu, separatismo muçulmano e nacionalismo secular.

Para nacionalistas hindus - defensores da ideia de que as crenças e a história dos hindus, na condição de população majoritária do país, deveriam fornecer a base ideológica para um 
Estado indiano concebido como um Estado hindu - e separatistas muçulmanos - para os quais a preservação da unidade nacional após a independência dependeria da possibilidade de se estabelecerem relaçôes de igualdade entre duas naçôes distintas, a hindu e a muçulmana -, a religião seria o fundamento da nacionalidade e da atividade política de modo geral.

A terceira corrente, o nacionalismo secular, afirmava que, devido às próprias diferenças entre hindus e muçulmanos, seria necessário dissociar religiáo e atividade política e reconhecer todos os cidadáos indianos como detentores de direitos iguais como indivíduos, e não como membros de uma religiáo específica (BRASS, 200I; KAVIRAJ, 1997).

No período imediatamente posterior à independência da Índia, observou-se a predominância da perspectiva nacionalista secular. Entre as implicaçôes de tal predominância para a construçáo da identidade nacional-religiosa hindu, deve-se destacar, em primeiro lugar, que a experiência da Partiçãó ${ }^{1}$ determinante para a adoção de uma Constituição secular, significou, em última instância, que demandas políticas baseadas em religião não seriam mais toleradas na Índia independente.

Em segundo lugar, em decorrência do assassinato de Gandhi por Nathuram Godse, um nacionalista hindu, o Corpo Nacional de Voluntários e a Hindu Mahasabha ${ }^{2}$ - organizaçóes das quais Godse havia sido membro - foram proibidos de atuar durante o período de I948-I949. Tratava-se, dessa forma, de um cenário desfavorável às atividades do movimento nacionalista hindu no interior das instituiçôes políticas indianas (BHATt \& MUKTA, 2000; Brass, op. cit.; KAVIRAJ, op. cit.).

É interessante observar que foi nesse cenário - caracterizado pela menor visibilidade do nacionalismo hindu na arena política indiana - que as organizaçóes nacionalistas hindus reformularam o discurso sobre a nação hindu, expandiram-se pela Índia e pelo exterior e elaboraram um discurso sobre a diáspora hindu.

Deve-se destacar a importância do Rashtriya Swayamsevak Sangh (Corpo Nacional de Voluntários, RSS) - principal organizaçáo nacionalista hindu contemporânea, fundada em 1924 - e de seu líder, Madhav Gowalkar, nesse processo. Gowalkar apresentou uma nova interpretação sobre um dos principais objetivos do nacionalismo hindu - a transformação do Estado indiano em um Estado hindu -, ao defender a "hinduizaçáo" da sociedade indiana e ao desenvolver novas técnicas para colocar em prática a ideologia do nacionalismo hindu no nível da sociedade (e não do Estado): a formação e a organização de homens treinados em shakhas

I Em linhas gerais, à época da independência da Índia, a questão muçulmana - reivindicação de um Estado independente para os muçulmanos - suscitou intensos debates e deliberaçóes em torno de duas alternativas: a criação de um único Estado, no qual prevalecesse a união entre hindus e muçulmanos, ou a criação de dois Estados - um Estado muçulmano e um Estado indiano. A última alternativa prevaleceu, e, em I947, foram criados o Paquistáo e a Índia. 2 A Hindu Mahasabha (Grande Assembleia Hindu) tinha por objetivo criar uma comunidade política hindu e definir a nação indiana por meio de símbolos extraídos exclusivamente de textos, crenças e práticas hindus. O presidente e o vice-presidente da Grande Assembleia, à época da fundação (1915), eram V. D. Savarkar, formulador da concepção original de Hindutva, e K. B. Hedgewar, fundador do Corpo Nacional de Voluntários (RSS), uma das principais organizaçōes nacionalistas hindus contemporâneas. 
(ramificaçôes) ${ }^{3}$, os swayamsevaks (voluntários), com vistas a difundir e reforçar samskars (visóes de mundo), como devoçáo pela terra materna, sentimento de fraternidade, reverência profunda pelos ideais de nação, disciplina, heroísmo e virilidade (Dixit, I986).

Os shakhas foram importantes não apenas para a difusão da ideologia nacionalista hindu no interior da sociedade indiana, mas, também, para a construção da identidade nacional-religiosa hindu entre os emigrantes.

Após o fim do período em que esteve proibido de atuar, o RSS criou várias outras organizaçóes, entre as quais se encontram o Vishva Hindu Parishad (Conselho Mundial Hindu, VHP), fundado em 1964, e o partido político Jana Sangh, criado em 1951, precursor do atual Bharatiya Janata Party (Partido do Povo Indiano, BJP), formado em I980.

As primeiras organizaçóes nacionalistas hindus no exterior foram ramificaçóes do RSS em países da África Oriental. O próprio RSS, quando narra sua história na diáspora, afirma que seu primeiro shakha fora da Índia foi formado em I946, a bordo de um navio que transportava trabalhadores, mercadores e visitantes que se dirigiam ao Quênia (BнAтT, 2000; BнATT \& MukTA, op. cit.).

A fundação das primeiras filiais de organizaçóes nacionalistas hindus no exterior, nas décadas de 1950 e 1960, insere-se em fluxos migratórios originados ainda no período colonial e mantidos no período posterior à independência - a emigração de comerciantes indianos para a África Oriental nas primeiras décadas do século XX -, assim como fluxos migratórios entre a Índia e o Reino Unido - a experiência africana pode ser considerada a primeira etapa de um processo duplo de emigração (da Índia para a África e desta para o Reino Unido).

No que se refere a essa fase inicial de expansão das organizaçóes nacionalistas hindus, deve-se destacar o fortalecimento da construção de uma identidade hindu homogênea pelos nacionalistas hindus. A criaçáo de um "ambiente de tradição" hindu relaciona-se ao fato de que os treinamentos intensivos e a transmissão de visôes de mundo de Hindutva ("hinduidade"), realizados nos shakhas, ocorreram em um país estrangeiro, o que amenizou as contestaçóes acerca da identidade indiana - existentes principalmente na Índia (LAL, 1997a; 1997b) - e favoreceu a construçáo de uma identidade exclusivamente hindu, com pretensóes à representação dos indianos como um todo.

Pode-se dizer que, em última instância, a presença no exterior fortaleceu o caráter nacional da identidade em questấo (BHATT, op. cit.). Além do mais, é possível observar, entre os emigrantes, a tendência de manutenção da ligação religiosa com a "Grande Tradição" hindu, por meio de missōes religiosas vindas da Índia, a partir do período colonial britânico - e não por meio da formaçáo de novas lideranças ou movimentos religiosos de inspiração hindu nas sociedades de destino.

Dessa forma, a construção de "ambientes de tradição religiosa" no exterior foi favorecida pela presença de grupos missionários como a Arya Samaj", além de Sai Baba e Hare Krishna, em

3 Shakha pode ser traduzido como ramo de árvore, o que remete à ideia, segundo os próprios nacionalistas hindus, de que os vários ramos (shakhas) ao redor do mundo formariam uma bela árvore.

4 Sociedade Ariana, organização reformista hindu fundada em I875 por Dayanand Saraswati. 
regiôes com número significativo de imigrantes indianos (Bhatt \& MukTA, op. cit.; Cohen, I997; VEER, I995; 200I).

Tendo por referência o RSS - o qual, por meio das atividades dos shakhas, procurou criar ambientes de tradiçẫo hindu nas sociedades de destino, enfatizando a formaçấo de indivíduos diretamente envolvidos com a causa do nacionalismo hindu contemporâneo -, o modo de atuaçáo do Conselho Mundial Hindu (VHP) representa uma ampliação do alcance do discurso nacionalista hindu contemporâneo, uma vez que dialoga com o ambiente de tradição religiosa dos emigrantes indianos (re)criado por missōes religiosas e por outras organizaçóes, inclusive o RSS.

Devido à maior flexibilidade de sua estrutura organizacional - não é constituído por centros de treinamento, como é o caso dos shakhas do RSS, mas suas atividades abrangem conferências mundiais, palestras, educaçáo, publicação de livros, recepçáo de sadhus que excursionam pelo Ocidente, etc. - e à utilização da estratégia de apelo ao que é familiar - apelo que se dirige especialmente aos devotos e, assim, mobiliza as massas de imigrantes hindus -, o Conselho consegue fazer com que a noção de "hinduidade" atinja não apenas os imigrantes hindus de classe média, principais apoiadores de Hindutva no exterior, mas, ainda, devotos hindus de classes baixas, que não sáo defensores declarados do nacionalismo hindu contemporâneo (MUKTA, 2000a).

Por fim, pode-se perceber que, diante da mencionada expansão de organizaçóes nacionalistas hindus para o exterior e do aumento da visibilidade de parte dos emigrantes indianos, as organizaçôes nacionalistas hindus, na Índia, rearticularam-se discursivamente, de modo a incorporar os emigrantes às narrativas sobre a nação hindu.

Gowalkar, ao discorrer sobre a identidade nacional hindu em sua obra Bunch of Thoughts, de 1966, referia-se à missão mundial hindu de salvar a humanidade de seu atual estado de degradação. A missão hindu foi identificada com a ideologia de Hindutva, e os agentes da missão, com os hindus vivendo no exterior, principalmente com aqueles organizados sob a égide dos grupos nacionalistas hindus - os swayamsevaks, voluntários da nação hindu -, considerados por Gowalkar os únicos capazes de "iluminar a humanidade" (Bнатт, op. cit.).

No que se refere ao discurso do Conselho Mundial Hindu sobre os emigrantes, observa-se que a definiçáo de hindu - para o VHP, hindu seria aquele que segue, respeita ou acredita nos "valores eternos da vida" que floresceram na Índia, não importa que ali tenha nascido ou que viva fora do país - permite fortalecer o sentimento de pertencimento dos emigrantes indianos à diáspora hindu - o "mundo hindu", compreendido pelo Conselho como uma "vasta sociedade hindu vivendo nesta terra [a Índia] e dispersa pelo globo em pequenas e grandes quantidades".

Deve-se ressaltar que a construção discursiva de um "mundo hindu" ou diáspora hindu se insere em um processo de reconstrução da percepçáo sobre os emigrantes, visto que, a princípio, o emigrante era depreciado pelos próprios hindus, por sua reduzida importância política e econômica e restriçóes de natureza religiosa.

É possível perceber que, paralelamente à manutenção da posição de obscuridade dos antigos emigrantes, ocorreu a construçáo de uma imagem positiva dos novos emigrantes. Tal imagem

${ }_{5}$ Eremitas ou mendicantes religiosos. 
está associada ao crescimento, verificado a partir de meados do século XX, da importância de hindus vivendo fora da Índia (BнAтT, op. cit.).

De modo mais específico, a nova percepção em questão remete a uma parcela dos indianos vivendo no exterior - especialmente em países desenvolvidos - e destaca seu sucesso econômico (LAL, 2004).

\section{SOBRE A DIÁSPORA: INTER-RELAÇÕES ENTRE NACIONALIDADE E TRANSNACIONALIDADE}

A autodefiniçáo "diáspora hindu" evidencia algumas das complexidades dos processos de construção de identidades culturais contemporâneos, especialmente no que se refere à relação entre nacionalismo e transnacionalismo. Estudar o modo como as dimensôes nacional e transnacional se relacionam envolve considerar a construção de identidades culturais por nacionais e emigrantes no interior de "ligaçôes transversais ou que cruzam as fronteiras dos Estados-naçáo" e de "inter-relacionamentos globalllocal, que não podem ser inferidos nos moldes de um Estadonação” (HALL, 2003b, p. II3).

Essa perspectiva aponta na direção de inter-relaçóes complexas de influência entre as dimensōes nacional e transnacional e, portanto, permite questionar duas das concepçóes predominantes, em se tratando de análises sobre identidades diaspóricas.

A primeira delas é a ideia de que diásporas são antinacionais, a qual estabelece uma relaçáo de oposição e até mesmo de superação entre nacionalismo e transnacionalismo. As identidades diaspóricas não apenas seriam antinacionais, como constituiriam uma noçáo de pertença alternativa às identidades nacionais (GrLRoY, 1997).

Tendo como referência a análise da identidade nacional-religiosa hindu - a qual, no período posterior à independência, com a expansão da rede de organizaçóes nacionalistas hindus para o exterior e a formulaçáo de um discurso sobre a diáspora hindu, adquire uma dimensão transnacional -, pode-se observar que não há uma relação de oposição entre o nacional e o transnacional.

Em primeiro lugar, levando-se em consideraçáo o próprio processo de formação de comunidades nacionais territorialmente definidas, no século XIX, percebe-se que a construção de identidades nacionais é indissociável de processos de globalização de longa duração e, portanto, de processos transnacionais (CalHoun, 200I; Hall, 2003b; VeER, I995).

É possível afirmar, dessa forma, que identidades nacionais foram construídas em um ambiente transnacional, o que, no caso indiano, remete ao período colonial britânico.

Deve-se observar, ainda, que, no caso da identidade diaspórica hindu, o reconhecimento de que existem inter-relaçóes complexas entre as dimensóes nacional e transnacional permite distinguir pelo menos três configuraçôes específicas de tais inter-relaçóes, caracterizadas antes por influência mútua que por oposição: a) a difusão da "hinduidade", tal como concebida pelos nacionalistas hindus contemporâneos, a partir da sociedade de origem, entre os emigrantes indianos; b) a articulação entre identidades construídas entre os próprios emigrantes e a ideo- 
logia de Hindutva nas sociedades de destino; c) a influência das identidades construídas entre os emigrantes, nas sociedades de destino, sobre as identidades formadas na sociedade de origem (MuKTA, 200ob).

A segunda concepçáo a ser questionada remete ao fato de que a análise de processos de construção de identidades diaspóricas habitualmente toma como ponto de referência as sociedades de destino. Identidades diaspóricas são, por um lado, associadas a pessoas inseridas em "culturas híbridas", em constante negociação "com as novas culturas em que vivem, sem simplesmente serem assimiladas por elas e sem perder completamente suas identidades" (HALL, 2003a, p. 88 - grifo meu), o que conferiria às culturas maior capacidade de articulaçáo entre o global e o local, o universal e o particular (CoHEN, op. cit.).

Por outro lado, como no caso da reidentificação com as culturas de origem em reação à xenofobia, as identidades diaspóricas são consideradas uma articulaçáo entre o local e o global, relacionada à (re)construção de vínculos simbólicos com um local, regiáo ou país específico, a partir das sociedades de destino (HALL, 2003a; 2003b). Contudo, a análise da "hinduidade" evidencia a possibilidade de formulaçáo de discursos sobre a diáspora a partir da sociedade de origem. Isso porque a "hinduidade" é uma identidade diaspórica construída a partir da sociedade indiana, em que coexistem as noçôes de pertença: a um Estado-nação (descrito como a "nação hindu") e a uma unidade sociocultural mais abrangente que o Estado-nação (o "mundo hindu").

Outro aspecto a ser destacado e problematizado está relacionado à definição de uma identidade diaspórica em termos religiosos. Deve-se ressaltar que, em se tratando dos movimentos migratórios originados a partir do Sul da Ásia, os termos "diáspora hindu" ou "comunidades hindus" sáo historicamente imprecisos e politicamente significativos (BHATT, op. cit.).

Quando se analisam identidades diaspóricas, é importante considerar que, entre as razóes de dispersão de grupos sociais, encontram-se não apenas eventos traumáticos - predominantes em diásporas de vítima, como a diáspora judaica -, mas, ainda, elementos voluntaristas relacionados à busca de trabalho, comércio ou ambiçóes coloniais - os quais caracterizam as diásporas de trabalho, mercantis e imperiais, respectivamente (CoHEN, op. cit.).

Observando os fluxos migratórios indianos ao longo da história, percebe-se que as motivaçôes para a dispersão foram diversificadas, sendo possível identificar principalmente diásporas de trabalho e mercantis (LAL, 1997a; 1997b). Dessa forma, a possibilidade de encontrar algo especificamente hindu em tais fluxos migratórios é muito reduzida. É nesse sentido que se considera imprecisa a utilizaçáo do termo diáspora hindu: quando se faz referência aos fluxos migratórios originados a partir da Índia, considera-se a emigração de indianos, e não exclusivamente de hindus. Tratar-se-ia, portanto, de uma diáspora indiana, e não de uma diáspora hindu.

A despeito de nâo haver indicaçôes de ocorrências que tivessem causado especificamente a emigração hindu, o tema da dispersão é empregado por grupos nacionalistas hindus contemporâneos, porque é politicamente significativo. A apropriaçáo de termos como "diáspora hindu" e a descrição de processos e histórias de migração complexos, em termos exclusivamente religiosos, estâo relacionadas ao objetivo de construir a imagem de uma diáspora especificamente religiosa 
e hereditária, o que permitiria, por um lado, fortalecer a autoidentificação - conferir aos grupos de emigrantes indianos um caráter de homogeneidade e reforçar o fato de que os indianos vivendo no exterior pertenceriam à nação hindu - e, por outro lado, delimitar diferenças entre os emigrantes hindus e os outros - ressaltar a "ferida hindu".

A "ferida hindu" está associada a um dos temas centrais do discurso nacionalista hindu contemporâneo - a responsabilização da conquista muçulmana e de seu longo governo sobre a Índia pela impossibilidade de emergência do país como uma nação - e, dessa forma, às disputas envolvendo a maioria hindu e a minoria muçulmana no interior da sociedade indiana (WARIAVWALLA, 2000).

As organizaçóes nacionalistas hindus contemporâneas dirigem duras críticas a políticos indianos que "apaziguariam" as minorias religiosas - muçulmanas, principalmente - por meio da concessão de direitos especiais a elas. A maioria hindu seria vitimada, assim, pela negligência e pelo oportunismo de políticos que "ferem" a comunidade religiosa dominante (hindu), ao deixarem de defender os interesses desta.

No que se refere ao discurso sobre a diáspora, esta é caracterizada pelos próprios nacionalistas hindus como uma diáspora de vítima - sáo evocados acontecimentos trágicos que teriam levado à dispersão do povo hindu, bem como a memória de uma terra natal perdida ou imaginada que ainda deve ser estabelecida -, apesar da dificuldade de se identificarem eventos traumáticos que tenham causado a dispersão de hindus.

Pode-se dizer que se trata de uma concepçáo fechada de identidade diaspórica, uma vez que enfatiza a diferença entre os hindus e todas as outras minorias étnicas no Ocidente (BHATT, op. cit.). Entre os emigrantes, tal concepção fechada de diáspora pode ser construída em reaçáo à xenofobia, levando-os à reidentificação com as culturas de origem, o que, por vezes, ocorre por meio do nacionalismo, como no caso daqueles que, antes da emigração, não pensavam em si mesmos como indianos, mas se tornaram indianos na diáspora (HALL, 2003b; VeER, 1995).

As razóes pelas quais os indianos no Reino Unido, por exemplo, adotam a denominação "hindu" são múltiplas e complexas, mas estão em grande parte relacionadas à sua condiçấo de minoria (RAJ, 2000). Tal condiçáo de minoria dos emigrantes hindus, nas sociedades de destino, favoreceria a identificação com a imagem da "ferida hindu" - e, portanto, a articulaçáo de identidades construídas entre os emigrantes e a "hinduidade" - mesmo onde obtiveram êxito econômico, como no caso de grupos de indianos que vivem nos Estados Unidos, visto que não gozam do mesmo status que os nacionais e não têm influência política.

É importante observar, ainda, que a articulação entre a "hinduidade" e as identidades construídas entre os emigrantes também exerce influência sobre as identidades formadas no subcontinente indiano. Deve-se levar em consideraçáo que os indianos que vivem no exterior constituem um modelo para as classes médias na Índia, o que implica que, além do modo de vida, a forte consciência de minoria dos emigrantes influencia as classes médias indianas, reforçando o discurso de vitimização hindu no interior da sociedade indiana. Além do mais, nas últimas décadas, as elites indianas, conjuntamente com emigrantes aliados à causa do nacionalismo hindu, adqui- 
riram posiçóes significativas de poder, por meio das quais podem empregar recursos materiais, políticos e culturais para pressionar as autoridades políticas indianas em favor de seus interesses. Ao se retratarem como "feridas", essas elites procuram exercer pressão política no interior do Estado indiano, no que obtêm o apoio de hindus vivendo no exterior (MUKTA, 2000a; 200ob).

\section{CONSIDERAÇÕES FINAIS}

Por meio da análise do processo de construção da identidade diaspórica hindu, é possível reconhecer a complexidade e a multiplicidade dos modos de articulação entre o nacional e o transnacional e questionar algumas das concepçóes correntes nos estudos sobre diásporas. Pode-se dizer que a relação entre as dimensóes nacional e transnacional é uma relação de influência mútua, por meio da qual processos transnacionais permitem a criação e o fortalecimento de identidades nacionais, bem como processos nacionais estimulam a criação e o fortalecimento de identidades diaspóricas.

Reconhece-se, aqui, a importância da influência da dimensão transnacional sobre a nacional, o que envolve o reconhecimento da importância do estudo de identidades construídas entre os próprios emigrantes, bem como da articulaçáo de tais identidades com discursos nacionalistas na sociedade de origem (Cohen, op. cit.; Hall, 2003a; MukTa, 200ob). Entretanto, tendo em vista os questionamentos sobre duas concepçôes usuais nas investigaçóes sobre identidades diaspóricas - o caráter antinacional das diásporas e a adoçáo das sociedades de destino como ponto de referência em tais investigaçôes -, suscitados pela análise preliminar da noção de "hinduidade", destaca-se aqui a influência da dimensão nacional sobre a transnacional. De modo mais específico, ressalta-se a importância de práticas e processos locais (nacionais) para a construção da dimensão global (transnacional).

Do ponto de vista da construção de identidades culturais, deve-se atentar para o fato de que a imigração e a etnicidade, ao lado da internacionalizaçáo do capital, são aspectos fundamentais do estágio contemporâneo de globalização. Isso porque formam um "conjunto de processos, por meio do qual elementos globais sáo localizados, os mercados de trabalho internacionais são constituídos e culturas do mundo inteiro são desterritorializadas e reterritorializadas" (SASSEN, 200I, traduçáo própria).

Dessa forma, processos locais (regionais/nacionais) não apenas sustentam a circulação de mercadorias, pessoas, fluxos financeiros e de informaçóes em âmbito global (internacional/transnacional), como também propiciam a formação de identidades transnacionais. É nesse sentido que se pode dizer que o nacional constrói o transnacional, tanto do ponto de vista material como do ponto de vista simbólico. 


\section{FONTES CONSULTADAS}

BнAтT, Chetan. Dharmo rakshati rakshitah: Hindutva movements in the UK. Ethnic \& Racial Studies, London, v. 23, n. 3, pp. 559-593, May 2000.

Bhatт, Chetan; Mukta, Parita. Hindutva in the West: Mapping the Antinomies of Diaspora Nationalism. Ethnic \& Racial Studies, London, v. 23, n. 3, pp. 407- 44I, May 2000.

Brass, Paul. The politics of India since independence. $2^{\text {nd }}$ edition. Cambridge: Cambridge University Press, 200I.

Calhoun, Craig. Multiculturalismo e nacionalismo, ou por que sentir-se em casa não substitui o espaço público. In: Mendes, Candido (Org.) Pluralismo cultural, identidade e globalização. Rio de Janeiro: Record, 200I.

Cohen. Robin. Global diasporas. An introduction. London: UCL Press, 1997.

Dixit, Prabha. The ideology of Hindu nationalism. In: Pantham, Thomas; Deutsch, Kenneth L. (Eds.) Political thought in modern India. New Delhi: Sage Publications, 1986.

Gilroy, Paul. Diaspora and the detours of identity. In: Woodward, Kathryn (Ed.) Identity and difference. Sage Publications: London, Thousand Oaks, New Delhi, 1997.

Gowalkar, M. S. Bunch of thoughts. Bangalore: Sahitya Sindhu Prakashan, 1996.

Hall, Stuart. A identidade cultural na pós-modernidade. Rio de Janeiro: DP\&A, $2003 a$.

Da diáspora. Identidades e mediaçóes culturais. Organização Liv Sovik. Belo Horizonte: Editora UFMG; Brasília: Representação da Unesco no Brasil, 2003b.

High Level Comitee on the Indian Diaspora. Report of the High Level Comitee on the Indian Diaspora. New Delhi, jan. 2002. Disponível em: <http://indiandiaspora.nic.in/>. Acesso em: 30 out. 2006.

Kaviraj, Sudipta (Ed.) Politics in India. New Delhi: Oxford University Press, I997.

LaL, Vinay. Reflections on the Indian diaspora. I997a. Disponível em: <http://www.sscnet.ucla. edu/southasia/Diaspora/diaspora.html>. Acesso em: Io abr. 2004.

. Vinay. The Indian diaspora. 1997b. Disponível em: <http://www.sscnet.ucla.edu/ southasia/Diaspora/diaspora.html>. Acesso em: Io abr. 2004.

. Labour and longing. Seminar, n. 538, June 2004. Disponível em: <www.india-seminar. com>. Acesso em: 07 nov. 2006. 
Madhok, B.; Rao, K. S. N.; Seshadri, H. V.; Sudarshan, K. S. Why Hindu Rashtra? Delhi: Suruchi Prakashan, I990. Disponível em: <http://www.hindubooks.org/whr/index.htm>. Acesso em: 28 jul. 2003 .

Mukta, Parita. The public face of Hindu nationalism. Ethnic \& Racial Studies, London, v. 23, n. 3, pp 442-466, May 2000a.

Romila Thapar. On historical scholarship and the uses of the past (interview with Parita Mukta). Ethnic \& Racial Studies, London, v. 23, n. 3, pp. 594-6I6, May 2000 b.

Office of the Registrar General \& Census Comissioner. Census of India. New Delhi, 200 . Disponível em: <www.censusindia.gov.in>. Acesso em: 25 mar. 2007.

Oliveira, Mirian S. R. de. O “mundo hindu”: identidade nacional e intolerância religiosa no discurso nacionalista hindu contemporâneo. 2007. Dissertação (Mestrado em Sociologia) -Fafich/ UFMG, Belo Horizonte, 2007.

Peralva, Angelina. Globalização, migrações transnacionais e identidades nacionais. Coesão Social na América Latina: bases para uma nova agenda democrática. São Paulo: Instituto Fernando Henrique Cardoso, 2008. Disponível em: <http://www.plataformademocratica.org>. Acesso em: 3I jan. 2009.

RAJ, Dhooleka Sarhadi. Who the hell do you think you are? Promoting religious identity among young Hindus in Britain. Ethnic \& Racial Studies, London, v. 23, n. 3, pp. 535-558, May 2000.

SASSEn, Saskia The global city: strategic site/new frontier. Seminar, n. 503, July 200I. Disponível em: <www.india-seminar.com>. Acesso em: 09 mai. 2009.

Savarkar, V. D. Hindutva: who is a Hindu? $6^{\text {th }}$ ed. Bombay: Veer Savarkar Prakashan, I989.

Schnapper, Dominique. De l'État-nation au monde transnational. Du sens et de l'utilité du concept de diaspora. Revue Européenne de Migrations Internationales, v. I7, n. 2, pp. 9-36, 200 . Disponível em: <http://www.persee.fr>. Acesso em: 28 jun. 2009.

Veer, Peter van der (Ed.) Nation and migration. The politics of space in the South Asian Diaspora. Philadelphia: University of Pennsylvania Press, I995.

Veer, Peter van der. Imperial Encounters. Religion and modernity in India and Britain. Princeton: Princeton University Press, 200I.

Wariavwalla, Bharat. Religion and Nationalism in India. Ram The God of the Hindu Nation. Round Table, London, v. 357, pp. 593-605, Oct. 2000. 
